Ocean Engineering

January 2016, Volume 111 Pages 34-42

http://dx.doi.org/10.1016/j.oceaneng.2015.10.040

http://archimer.ifremer.fr/doc/00294/40557/

(c) 2015 Elsevier Ltd. All rights reserved.

\title{
Bubble sweep-down occurrence characterization on Research Vessels
}

\author{
Delacroix Sylvain ${ }^{1}$, Germain Grégory ${ }^{1,{ }^{*}}$, Berger Laurent ${ }^{2}$, Billard Jean-Yves ${ }^{3}$ \\ ${ }^{1}$ IFREMER, Marine Structures Laboratory,150 Quai Gambetta, 62321 Boulogne-sur-Mer, France \\ 2 IFREMER, IMN NSE AS, 29280 Plouzane, France \\ 3 IRENAV, Ecole Navale, 29240 Brest, France \\ * Corresponding author : Grégory Germain, email address : gregory.germain@ifremer.fr
}

\begin{abstract}
:
Bubble sweep-down on oceanographic vessels generates acoustic perturbations. We propose in this work to characterize the sub-surface bubbles occurrence conditions from acoustic data analysis acquired during surveys in relatively shallow water with the IFREMER research vessels Thalassa and Pourquoi Pas?. The methodology of data analysis used in this work allows us to characterize the sailing conditions influence on bubble sweep-down occurrence. The correlation between sailing conditions and acoustic perturbations tends to demonstrate that the presence of bubbles under the hull is clearly related to the wind speed and natural aeration, and that surface bubbles are advected differently in the water column by the two vessels
\end{abstract}

\section{Highlights}

- Characterization of sub-surface bubbles occurrence conditions from acoustic data analysis. - Correlation between sailing conditions and acoustic perturbations. Bubbles distribution comparisons demonstrate the effect of bubble sweep-down.

Keywords : Bubble sweep-down, Acoustic perturbation, Ship motion

\section{Introduction}

The generation of bubbles in the open ocean has been the topic of several works, most often motivated by a better understanding of gas exchanges with the atmosphere. Thorpe [18] describes the fact that small bubbles, of radius 
less than about $1 \mathrm{~mm}$ are stabilized by surface tension while those of larger radius are fragmented by shear stresses in the turbulent motion induced by the breaking event. The smaller bubbles rise very slowly and are consequently more persistent in the water column and often advected at a greater depth.

Movements of the surface ship bow is a source of air bubbles generation. While the ship is moving, these bubbles may be entrained under the hull where the transducers are mounted. This phenomenon of bubble sweep-down is an issue of major importance for oceanographic vessels designers. Air bubbles passing under sounders location may absorb or reflect the acoustic wave and be a source of inconvenient noise affecting sonar's data. Such disturbances strongly affect the productivity of some vessels dedicated to acoustic survey, as we can see on figure 1. On this figure we can see the perturbation induced on one ping for sea bottom detection by a multibeam sounder Reson Seatbat 7150 used at $24 \mathrm{kHz}$ on the IFREMER research vessel Pourquoi Pas ?. The horizontal red line is the seabed detection at $2180 \mathrm{~m}$ depth: the detection is well marked without acoustic perturbation (figure 1 bottom) while it can be undetected for the perturbed ping (figure 1 top). In this extreme case, the acoustic wave is completely absorbed in the bubble layer and the transmitted pulse doesn't reach the seafloor, thus no echo can be observed. During the receiving time, the high noise level is attributed to the broadband noise of the bubbles collapsing in front of the transducer. This kind of perturbation is not only due to ship motions but by a combination of factors from which wave/bow interactions play an important part.

Many studies have therefore been dedicated to this topic since Dalen \& Løvik [1] who investigated bubbles effects on biomass estimation of aquatic targets using echo-integration technique, first described by Dragesund \& Olse [6] and now widely adopted in fishery research. The purpose of their work was to find an empirical formula, that would enable the prediction of acoustic signal attenuation depending on weather conditions. Novarini \& Bruno [13] also studied the effect of bubbles layer on sound propagation. Later, New [12] exposed the progress performed in oceanography thanks to the wider use of 


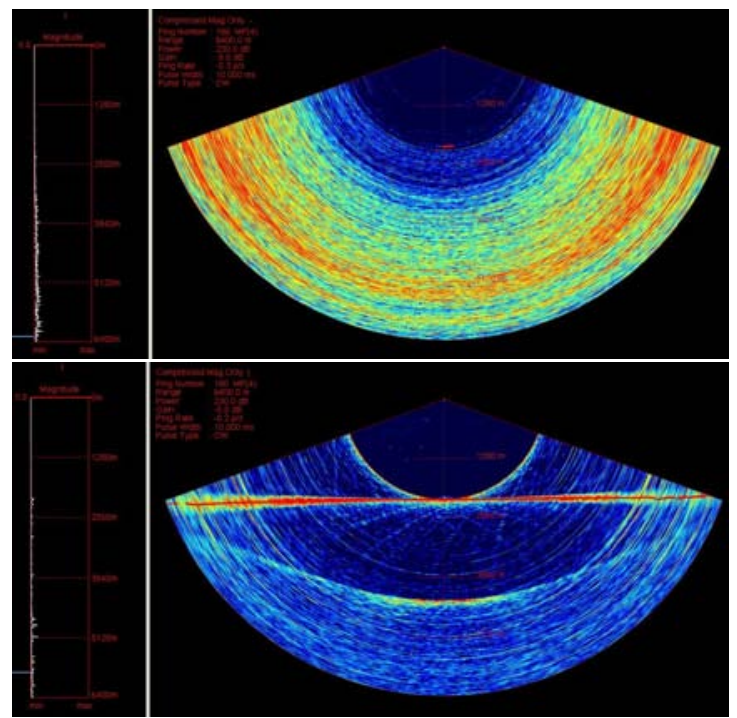

Figure 1: Comparison between a "bubbled" ping (on top) and a non perturbed ping (bottom) from a multibeam sounder acquired in the same conditions on the Pourquoi Pas ? $(\mathrm{dt}<1$ minute). The horizontal red line is the seabed detection.

Acoustic Doppler Current Profilers on research vessels. However, New pointed out that problems remained under more or less bad weather conditions because of interferences generated by the near surface bubbles layer that can be overcome by lowering the transducer below the bubbles layer. Trevorrow [21] developed in 2003 an analytical model to determine the influence of bubbles on high-frequency sonar performances. Finally, Shabangu \& al. [15] compared the attenuation of acoustic signals caused by bubbles for different sorts of transducer installations. Conclusions of these works are to recommend the installation of the transducers as deep as possible to avoid the under hull bubble layer and significant acoustic signal attenuation for wind speed above $10 \mathrm{~m} / \mathrm{s}$. This solution is not always possible or efficient and solutions to minimize this phenomenon are still being sought [Rolland \& Clark [14]].

For that purpose comparison of bubbles generation should be undertaken for several oceanographic vessels. Nonetheless there are many parameters controlling this issue (hull characteristics, wind and sea state, heading, ship's velocity 
and motions, depth, ...) and the conditions of occurrence of this phenomenon are consequently still poorly known. The objective of this study is to find a methodology for the analysis of acoustic data allowing the prediction of bubble generation under the hull of research vessels. Here we propose a first study to characterize the bubbles occurrence conditions.

The data used for this work come from the french survey series International Bottom Trawl Survey (IBTS) 2010-2013 undertaken in winter (January/February) in the Channel and the North Sea with the research vessel Thalassa. After the presentation in the second section of the equipments and the methodology of data analysis used in this work, the main results in term of sailing conditions influence on bubble sweep-down occurrence are exposed. The main advantage of direct measurement of bubble backscatter, over the method proposed by Shabangu \& al. [15] to measure the attenuation on the seafloor echo is to avoid the influence of the variation of the seafloor backscatter for characterising the attenuation and hence the bubbling. Once the bubbling is detected, prediction of attenuation can be done based on models of bubble size distribution and individual bubble backscattering cross-section [Weber [23]]. A correlation between wind speed, sailing conditions and acoustic perturbations is attempted and a comparison between the Ifremer research vessels, Thalassa and Pourquoi Pas?, is given to prove the consistency of the methodology of acoustic data analysis for bubble sweep-down detection.

\section{Material and methods}

\subsection{Eastern Channel and North Sea case study}

The research vessel Thalassa is one of the main fisheries research vessel of Ifremer fleet. The primarily assignments of this vessel deal with fisheries-based missions such as population ecology and assessment of fish stocks. For this purpose, in addition to traditional fishing equipment, Thalassa is equipped with six Simrad ER60 echosounders (18, 38, 70, 120, 200 and $333 \mathrm{kHz}$ ) and a Sim- 
rad ME70 multibeam echosounder in the range 70-120 kHz [Trenkel \& al. [19]]. All equipments are calibrated regularly in order to provide absolute acoustic backscatter measurements of the water column and the seafloor. These transducers are installed close to each other, as shown in figure 2, to ensure that the different echosounders observe as much as possible the same scenes [Korneliussen \& al. [7]]. Ship's motions are recorded from an inertial measurement unit with a frequency of $10 \mathrm{~Hz}$. Remaining information related to this study, like ship velocity and heading, wind speed and direction, are recorded from all sensors every 30 seconds and synchronized by the mean of a custom acquisition system.

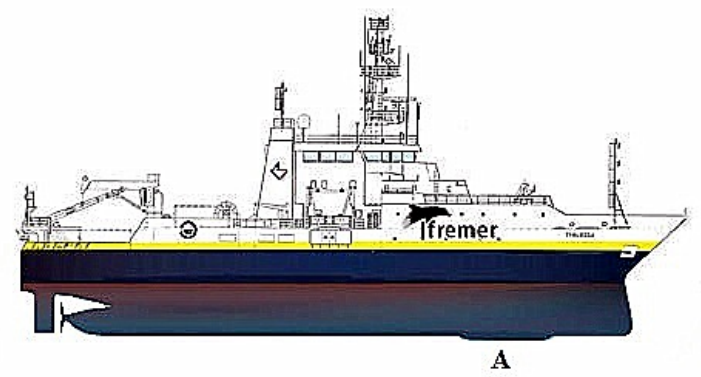

Figure 2: The Thalassa with Echosounders position noted A

As part of the International Bottom Trawl Survey, the Fishery Resources Laboratory of the IFREMER North Sea-Channel Center is conducting a onemonth annual IBTS cruise in the eastern English Channel and in the North Sea. Carried out in collaboration with six European partners and coordinated by the International Council for Exploration of the Sea (ICES), this research cruise on the research vessel Thalassa is undertaken to calculate abundance indices for the main commercial species caught in this area.

Acoustic samples collected during three IBTS cruises, between 2010 and 2013 are considered in this work. During these periods, the Thalassa activities are concentrated in the east Channel (see the route of the Thalassa during the first week of IBTS 2013 on figure 3) and a part of the North Sea. This working area 
is characterized by shallow water, for a mean depth close to $50 \mathrm{~m}$ and always lower than $150 \mathrm{~m}$. The maximal value of the true wind encountered is 72 knots $(36 \mathrm{~m} / \mathrm{s})$. The significant wave height, defined as the mean of the highest third of the waves, is between 0,5 and $3,5 \mathrm{~m}$, with a maximal wave period of $9 \mathrm{~s}$.

The first step of the data analysis consists in a selection of measurement periods which can be analyzed. Such periods are automatically defined by stable sailing conditions (velocity and heading) for a duration of 20 minutes. Then ship's motions, especially pitch and heave, are analyzed on these periods and finally acoustic disturbances are quantified. By this way all these stable periods form a database allowing a statistical research of the factors of bubble generations.

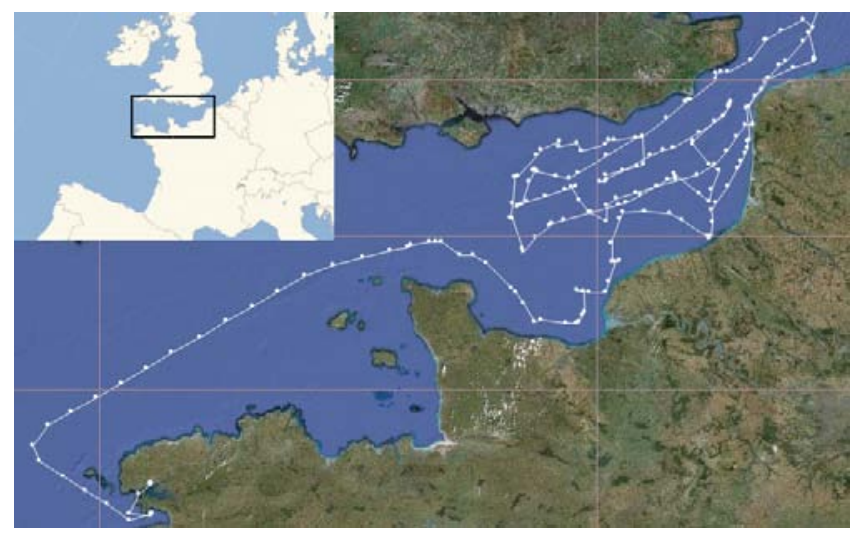

Figure 3: Route of the Thalassa during the first week of IBTS 2013 cruise in the eastern Channel, North of France

\subsection{Methodology of acoustic data analysis}

Quantifying the disturbances on acoustic signals due to the presence of air bubble clouds under the hull is a complex problem. Different phenomena possibly happen: bubbles may reflect partially or completely the acoustic waves, but also absorb it. Reflection and absorption occur along the propagation path of the acoustic wave and masking can occur for the transmitted and/or the reflected wave, depending on the spatial extent of bubble clouds. Disturbances 
range from insignificant attenuation to complete loss of data. Bubble bursting can be as well a source of additional noise.

This study is limited to the quantification of the backscatter signal on clouds of bubbles images by the echosounder (absorption and bubble bursting are not considered here). The variations of backscatter, in a layer just under the hull ("layer 1", between $2 \mathrm{~m}$ and $4 \mathrm{~m}$ under the sonar, with ship's movements compensation), are considered to be only due to the quantity of air bubbles in this layer. Considering a volume $V$, the volume backscattering strength $\left(S_{v}\right)$ is defined as MacLennan \& al. [10]:

$$
S_{v}=10 \log \left(\frac{\sum \sigma_{b s}}{V}\right)
$$

with $\sigma_{b s}$ the backscattering cross-section:

$$
\sigma_{b s}=\frac{r^{2} I_{b s}(r) 10^{\alpha r / 10}}{I_{i n c}}
$$

where $r$ is the distance of the measurement position from a small target, $I_{b s}(r)$ is the intensity of the backscattered wave, $I_{i n c}$ is the intensity of the incident wave at the target, and $\alpha$ is the acoustic absorption coefficient depending of the temperature and salinity of seawater but principally of the wave frequency.

The mean of the volume backscattering strength $S_{v}$ is calculated in the layer 1 for each impulse (ping) of the echosounder by the software Movies 3D, developed by Ifremer [Trenkel \& al. [20]], with minimum and maximum thresholds respectively -100 and $0 d B$. For each measurement period of the database previously defined, the presence of bubbles can be quantified by the fluctuations of $S_{v}$ by the following method based on the work of Trevorrow [21].

According to Medwin \& Clay [11], the backscattering cross-section per unit volume of a bubbles cloud $\left(s_{v}\right)$, with $S_{v}=10 \log \left(s_{v}\right)$, ignoring multiple reflections, can be calculated by:

$$
s_{v}(f, z)=\int_{0}^{\infty} \sigma_{b s}(a, f) \cdot n(a, z) d a
$$

where $n(a, z)$ is the bubble size distribution in the cloud, $a$ the bubble radius, $z$ the depth and $f$ the signal frequency. $\sigma_{b s}$ is the acoustic scattering cross section 
of a single bubble:

$$
\sigma_{b s}(a, f)=\frac{a^{2}}{\left(\left(f_{R} / f\right)^{2}-1\right)^{2}+\delta^{2}}
$$

with $\delta$ the damping constant, taken equals to $k a$, by ignoring the damping due to shear viscosity and the damping due to thermal conductivity. The resonant frequency $f_{R}$ for a given bubble radius $a$ is:

$$
f_{R}=\frac{\sqrt{3 \gamma P_{0} / \rho}}{2 \pi a}
$$

with $\gamma$ the heat capacity ratio $\left(=1,4\right.$ for air), $P_{0}$ the static pressure on the bubble $\left(=P_{a t m}+\rho g z\right)$ and $\rho$ the density of seawater.

An expression for the bubble size distribution must be used. It is currently admitted that breaking waves create clouds of bubbles whose void fraction can reach a value of $10 \%$ very close to the surface [Lamarre \& Melville [8]]. Deane \& Stokes $[2,3]$ developed an optical system capable of recording bubbles of radii $>200 \mu \mathrm{m}$. Two mechanisms controlling the bubbles size are identified. For bubbles larger than about $1 \mathrm{~mm}$ the density is proportional to the bubble radius to the power of $-10 / 3$ and smaller bubbles follow a density with a $-3 / 2$ power-law scaling. Thorpe \& al. [17], Thorpe [18] described the fact that small bubbles (radius $<1 \mathrm{~mm}$ ) are stabilized by surface tension while those of larger radius are fragmented by shear stresses. On the opposite, very small bubbles, with a radius smaller than about $30 \mu m$, are also unstable. Many of the gaseous content pass rapidly into solution and bubbles eventually dissolving completely. In this case, the bubbles size distribution usually decreases with decreasing bubble radius. However small bubbles with a very low rise velocity are more persistent in the water column, at a greater depth. It is therefore appropriate to use a bubbles size distribution that include radii between around $30 \mu \mathrm{m}$ and $1 \mathrm{~mm}$. Vagle \& Farmer [22] found by acoustic measurements that the density of bubbles of radii greater than $20 \mu \mathrm{m}$ can be described, for a depth of $0,5 \mathrm{~m}$, by the relation:

$$
n(a)=n_{0} \cdot \exp (-a / 34)
$$

with $n_{0}$ the characteristic density. Trevorrow [21] used this spectra with an 
exponential decay with depth:

$$
n(a, z)=n_{0}(z) \cdot \exp (-a / 34), \quad \text { with } n_{0}(z)=n_{0} \cdot \exp (-z / d)
$$

with $d$ the critical depth. With such distribution, the backscattering equation becomes:

$$
s_{v}(f, z)=n_{0}(z) \int_{20}^{1000} \sigma_{b s}(a, f) \cdot \exp (-a / 34) d a
$$

Consequently measurements of $S_{v}$ enable an estimation of $n_{0}(z)$ and the determination of the Void Fraction:

$$
V F=\int_{20}^{1000} \frac{4}{3} \pi a^{3} n(a, z) d a
$$

An adequate threshold is then searched for the detection of bubbles. A threshold of $S_{v}=-50 \mathrm{~dB}$ for the $120 \mathrm{kHz}$ echosounder effectively separates bubbles and plankton scattering contribution. For a depth of $9 m$ (included in the layer between $2 \mathrm{~m}$ and $4 \mathrm{~m}$ under the sonar) the void fraction corresponding to $-50 d B$ is $2,2 \cdot 10^{-10}$. Indeed a lower volume backscattering strength corresponds to an insignificant bubble density. All these elements lead to the calculus of a "bubbled" ping ratio (ping with $S_{v}>-50 d B$ ) at different layer for all stable periods.

The influence of sonar frequency on bubble detection is shown on figure 4 . The graphic on the left represents the ratio of bubbled ping (with a $-50 d B$ threshold) for the mean wind speed of the measurement periods and for the different sonar frequencies. The detection of bubble is higher for $120 \mathrm{kHz}$ and slightly lower for 70 and $200 \mathrm{kHz}$. The detection is reduced for $38 \mathrm{kHz}$, and almost non-existent for $18 \mathrm{kHz}$. This evolution can be explained by the distribution of bubbles, characterized by a majority of less than $100 \mu \mathrm{m}$ radius bubbles. Such bubbles have high resonance frequencies as can be seen on the right graphic for a $50 \mu \mathrm{m}$ radius bubble, which resonance frequency is close to $120 \mathrm{kHz}$.

The use of the echosounder ER60 at $120 \mathrm{kHz}$ seems therefore the most appropriate to study bubbles generation under the hull. In the following section the results are presented for this frequency. 

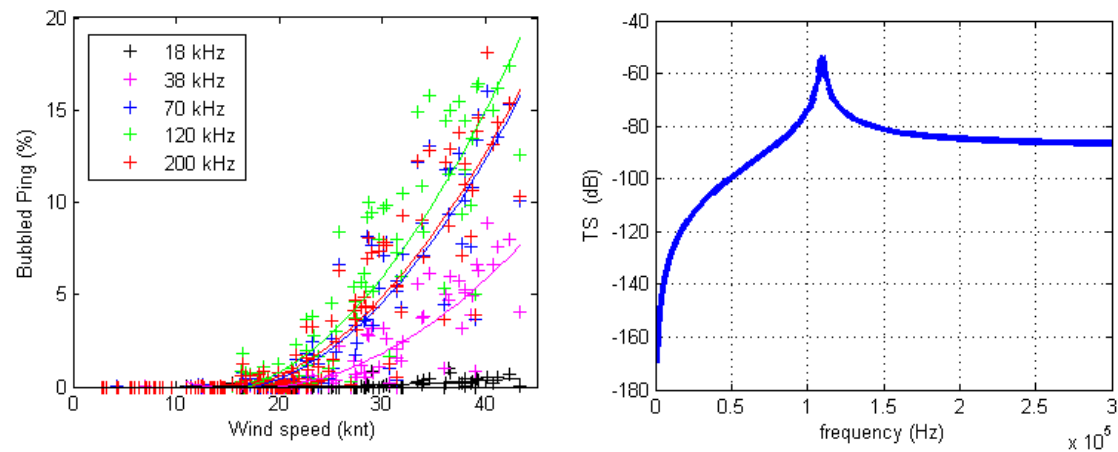

Figure 4: Left: Influence of sonar frecuency on bubble detection. "Bubbled" Ping vs Pitch in the layer 2-4 $\mathrm{m}$ under the hull. Right: Target Strength vs frecuency for a $50 \mu \mathrm{m}$ radius bubble at $9 m$ deep

\section{Analysis of IBTS data}

Previous studies have shown the main role of pitch motion on bubbles generation. The purpose of this research is both to have a better understanding of pitch motion influence and also to study the influence of other parameters such as wind speed and natural aeration in the open ocean.

\subsection{Influence of pitch and wind speed}

The first part of the study has been made with data from IBTS 2010 and 2011 and the first week of the 2013 survey. Following the analysis described above, a matrix of data is obtained. Each line of this matrix corresponds to a measurement period defined in section 2. Each row corresponds to a navigation parameter mentioned above or an indication of bubbling. These data are illustrated in table 1, where are given the minimum, mean and maximum on all the periods of the mean value of the true Wind (W) and the ship Velocity $(\mathrm{V})$, the standard deviation of Pitch $(\sigma \mathrm{P})$, Heave $(\sigma \mathrm{H})$ and Roll $(\sigma \mathrm{R})$, the mean and standard deviation of $S_{v}$ and the ratio of "Bubbled" Ping (BP) as index of bubbling. 


\begin{tabular}{|c||c|c|c|c|c||c|c|c|}
\hline & $\mathrm{W}(\mathrm{kt})$ & $\mathrm{V}(\mathrm{kt})$ & $\sigma \mathrm{P}\left(^{o}\right)$ & $\sigma \mathrm{H}(\mathrm{m})$ & $\sigma \mathrm{R}\left(^{o}\right)$ & $S_{v}(\mathrm{~dB})$ & $\sigma S_{v}(\mathrm{~dB})$ & $\mathrm{BP}(\%)$ \\
\hline \hline min & 3 & 6 & 0,1 & 0,0 & 0,3 & $-97,6$ & 2,6 & 0 \\
mean & 21 & 11 & 0,6 & 0,2 & 0,9 & $-87,2$ & 9,7 & 2,9 \\
$\max$ & 43 & 13 & 2,6 & 0,9 & 2,4 & $-67,8$ & 21,2 & 20,4 \\
\hline
\end{tabular}

Table 1: Minimum, mean and maximum of the main parameters over all the periods

In order to highlight the most important parameters for the generation of bubbles, the correlations between the main characteristic parameters mentioned above and the ratio of "bubbled" ping have been studied. Delacroix [4] has shown that ship velocity, heave and roll play an insignificant part in the phenomenon occurence. In this work, we focus on the role played by the pitch and the wind speed on bubble clouds appearance. To this aim, figure 5 represents the ratio of "bubbled" ping in a period as a function of the pitch standard deviation.

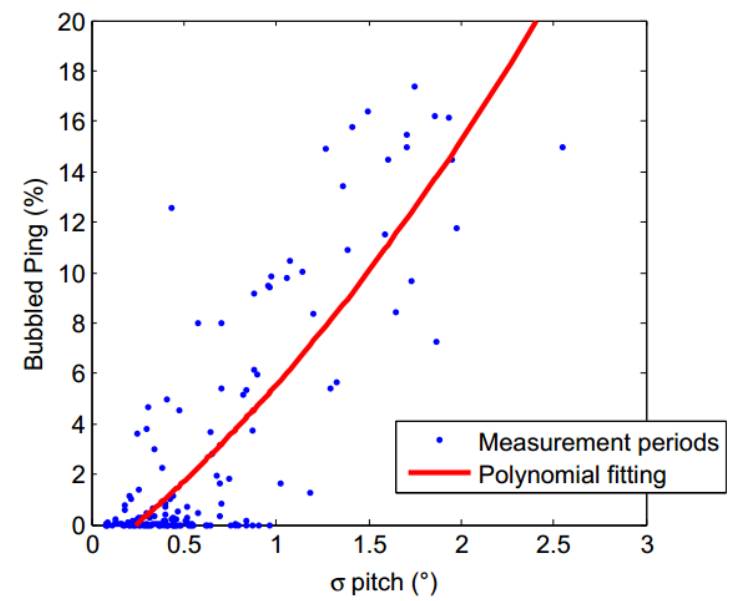

Figure 5: Influence of pitching on bubble generation. "Bubbled" Ping vs Pitch in the layer 1 (2-4 $\mathrm{m}$ under the hull) for all measurement periods and $2^{\text {nd }}$ order polynomial fitting

The influence of pitch motion on bubble generation and propagation under the hull is thus shown. The index of correlation used is the coefficient of 
determination $R^{2}$ defined as:

$$
R^{2}(X, Y)=\left(\frac{\operatorname{COV}(X, Y)}{\sigma(X) \sigma(Y)}\right)^{2}
$$

where $\sigma(X)$ is the standard deviation of the variable $\mathrm{X}$, and $C O V(X, Y)$ the covariance between $\mathrm{X}$ and $\mathrm{Y}$. As expected, there is a strong link between bubbling and pitching $\left(R^{2}=0,72\right)$. Bubbles are always present for a pitch standard deviation higher than $1^{\circ}$.

The correlation between the generation of bubbles and the wind is even stronger. Figure 6 represents the ratio of "bubbled" ping as a function of the wind speed. The coefficient of determination is this time higher: $R^{2}=0,84$. A critical value of the wind speed $\left(W_{c}\right)$ can be defined, corresponding to the minimum of wind speed to observe a non-negligible bubbles density in this layer. This value is obtained when the best second order polynomial fitting reach a ratio of "bubbled" ping of $1 \%$. In this layer, the wind speed critical value is $W_{c}=21 \operatorname{knots}(10 \mathrm{~m} / \mathrm{s})$.

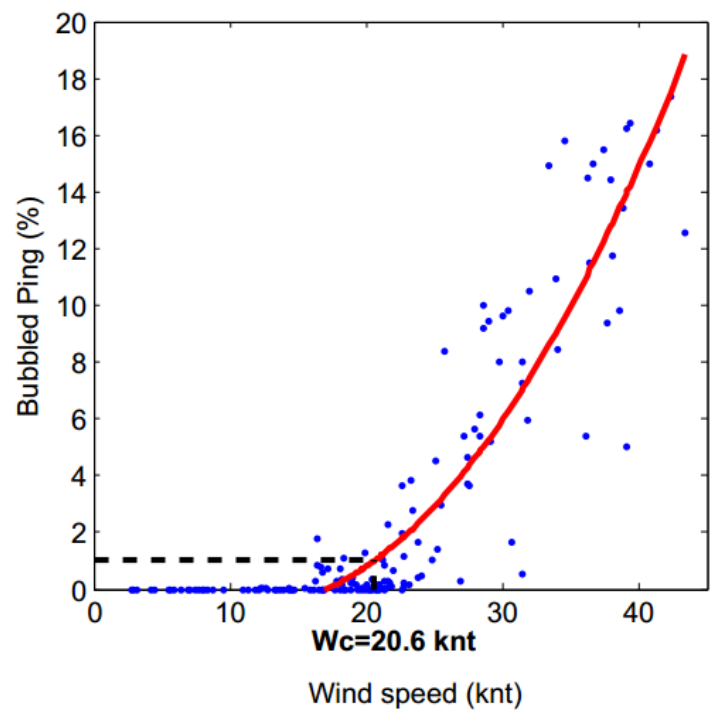

Figure 6: Influence of wind speed on bubble generation. "Bubbled" Ping vs Wind Speed in the layer 1 (2-4 $\mathrm{m}$ under the hull)

These calculations have been repeated for the three other layers under the 
first one (layers 2, 3 and 4 respectively between 4 and $6 \mathrm{~m}, 6$ and $8 \mathrm{~m}, 8$ and $10 \mathrm{~m}$ under the sonar) as shown in figure 7. The shapes of these graphs are similar than for the first layer but the ratio of "bubbled" ping decreases with depth. On the contrary, the wind speed critical value increases with depth as reported in table 2 .

\begin{tabular}{|c|c|c|c|c|}
\hline Layer & Distance $(\mathrm{m})$ & Mean Depth (m) & BP max (\%) & Wc (knt) \\
\hline \hline 1 & $2-4$ & 9 & 18 & 21 \\
2 & $4-6$ & 11 & 16 & 23 \\
3 & $6-8$ & 13 & 7 & 29 \\
4 & $8-10$ & 15 & 3 & 38 \\
\hline
\end{tabular}

Table 2: Distance under the sonar, mean depth, maximum of "Bubbled" ping and critical wind speed for the 4 layers

These observations confirm the interest to install transducers at the greater possible depth. Whenever possible, sonar mounts like keel fairing or gondola will increase the wind speed critical value and increase therefore workable sea states, which would be an important achievements for the productivity of the ship.

Pitch and wind speed are also correlated between each other. Periods during which the standard deviation of pitch is higher than $1^{\circ}$ correspond to wind speed higher than 25 knots $(12.75 \mathrm{~m} / \mathrm{s})$. It is therefore difficult to distinguish causes and consequences but the stronger correlation between bubble generation and the wind speed suggests that the wind is the major factor of bubble clouds generation in these cases. For some high wind speed values, the pitch can reach low values as well as very high ones. Moreover for some low values of pitch (standard deviation $<0,5^{\circ}$ ), important ratio of "bubbled" ping can still be observed (more than 10\%).

It is therefore rightful to wonder if these bubbles are generated by the ship itself or if they are naturally created by surface turbulence at high wind speed. 

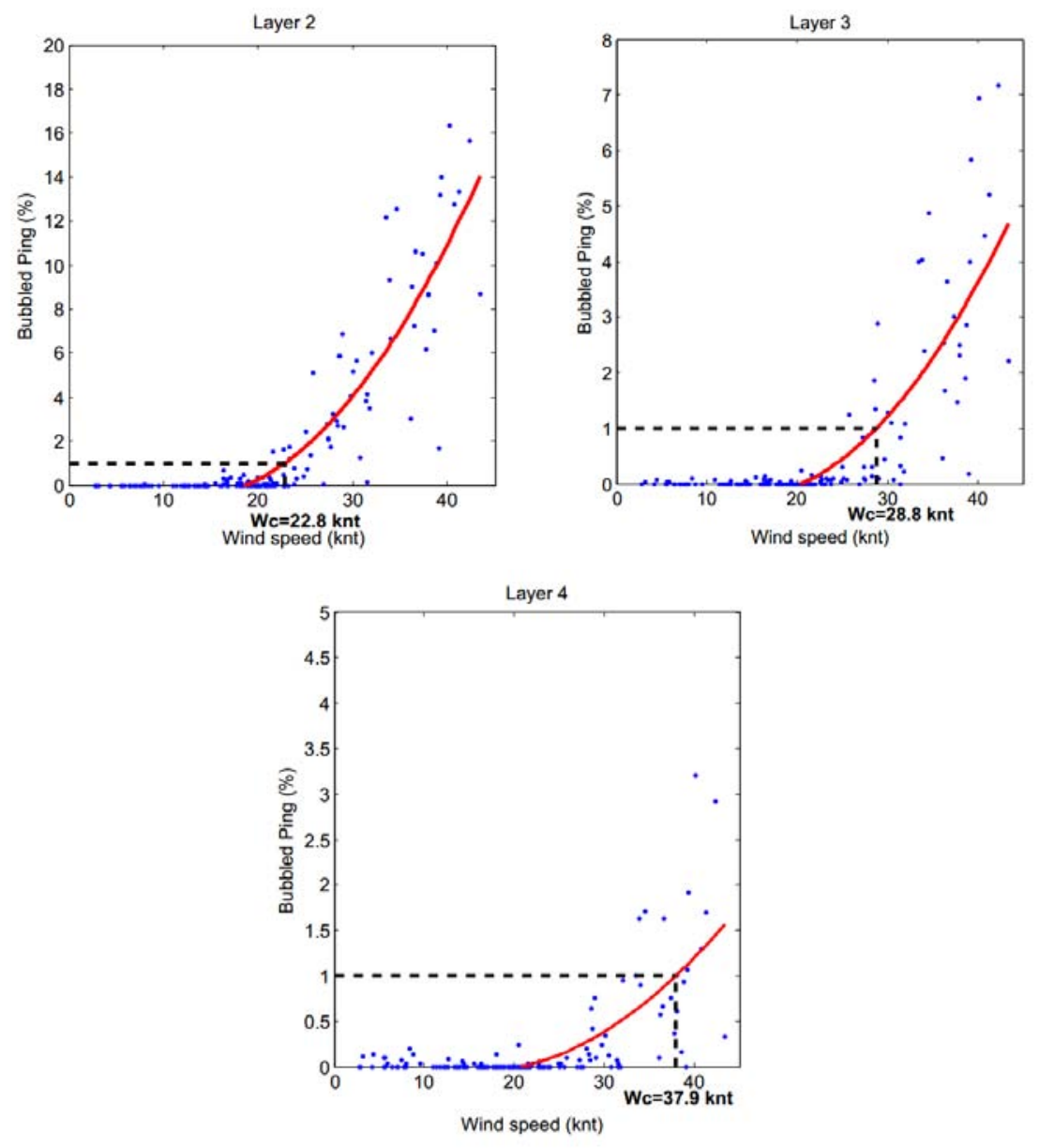

Figure 7: Influence of depth on bubble generation: ratio of "bubbled" ping vs wind speed for layers 2,3 and 4 respectively between $4-6 \mathrm{~m}, 6-8 \mathrm{~m}$ and $8-10 \mathrm{~m}$ under the sonar.

For that reason a horizontally steered echosounder has been used during the 2013 survey, to study bubbles occurrence close to the free surface of the sea without ship influence.

\subsection{Analysis of horizontally steered echosounder data}

During fishery acoustic surveys, a horizontally steered ER60 echosounder at $120 \mathrm{kHz}$ can be mounted in a tube located at the center of the vessel in order to cover the acoustic surface blind zone of the vessel and then reduce 
possible bias in the assessment with vertical echosounders. This sounder is oriented horizontally, to starboard (see figure 8), allowing the observation of the sea surface layer to assess the quantity of bubbles in the water column. The objective is to distinguish bubbles generated by ship motions from natural bubbles present below the ocean surface, as we can see on figure 9 .

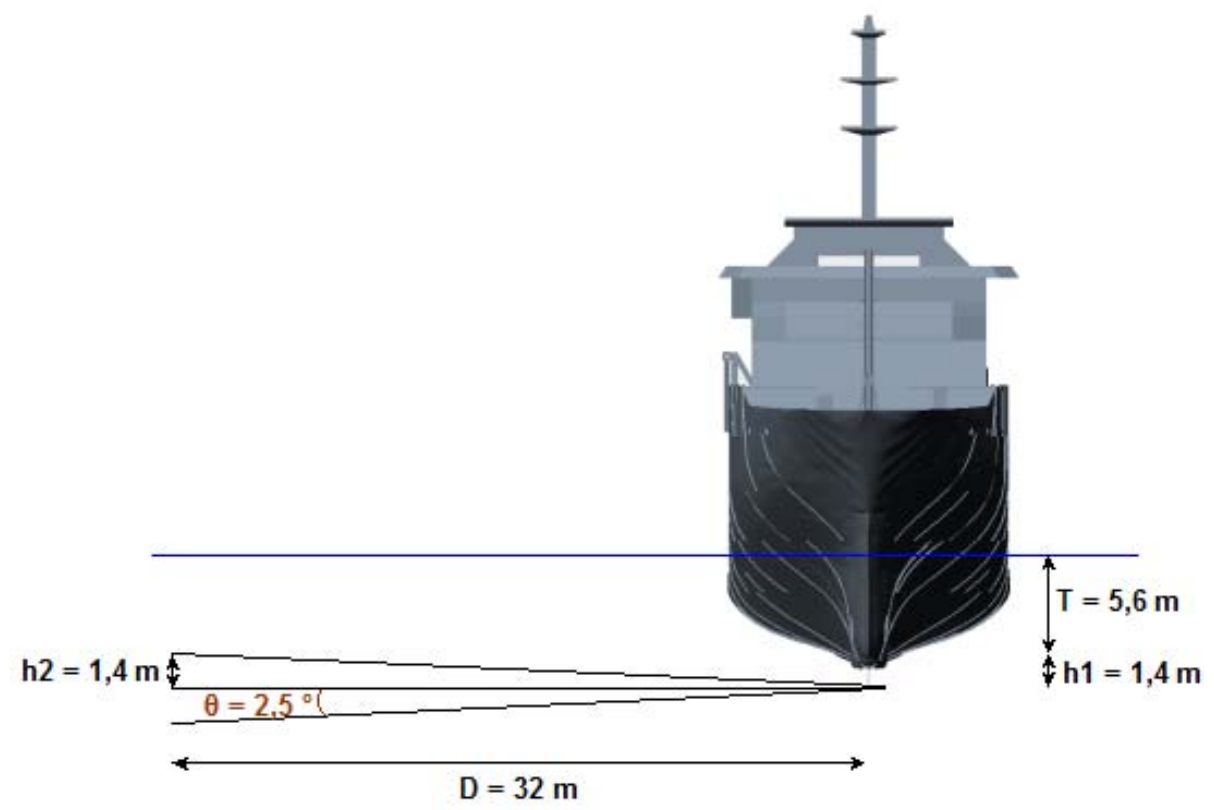

Figure 8: Drawing of the layer studied with the horizontal echosounder under the Thalassa

The analysis of horizontally steered echosounder data requires some precautions. First of all, a layer must be determined sufficiently far from the ship to make sure that the reflections measured are not due to the bubbles generated by its motions nor its bow wave. It has been demonstrated by Lord Kelvin in 1887 that ship bow generates a wake with a constant angle of $19,5^{\circ}$ from the ship's route. Taking into account the beam of the ship $(14,90 \mathrm{~m})$, this bubbly wake would be up to a distance of $20 \mathrm{~m}$ from the horizontal echosounder at midship. The signal may also be reflected by the free surface or the seabed, especially when the ship is rolling. For these reasons data have been filtered to take into account in the analysis only the pings corresponding to a roll between 


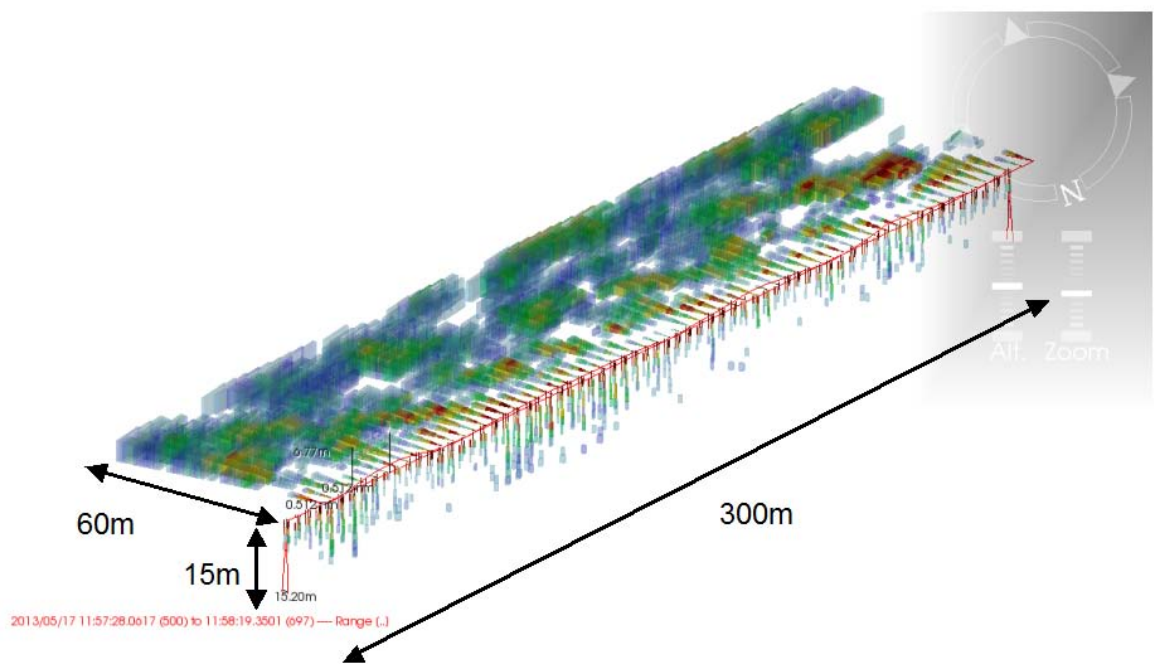

Figure 9: Illustration of the acoustic perturbations at the sub-surface from horizontal sounder measurements

$0^{\circ}$ and $2^{\circ}$ toward the seabed. Considering all these elements, a layer has been chosen between 30 and 32 meters from the sonar. In this layer, the minimum depth reached in the beam width at $-3 d B$ is $5,6 \mathrm{~m}$ with a roll of $0^{\circ}$, and the maximum is $9,5 \mathrm{~m}$ with a $2^{\circ}$ roll.

The mean depth seen by the horizontal echosounder is $7 \mathrm{~m}$ while the mean depth of the first layer for the vertical echosounder is $9 \mathrm{~m}$. It has been shown in section 2.2 that a threshold of $-50 d B$ corresponds to a void fraction $V F=$ $2,2 \cdot 10^{-10}$ for a depth of $9 \mathrm{~m}$. Taking $d=1 \mathrm{~m}$ in the distribution of bubbles (equation 7), $n_{0}$ is obtained and the distribution of bubbles at $7 \mathrm{~m}$ depth is determined:

$$
n(a, 7)=n_{0} \cdot \exp (-7 / d) \cdot \exp (-a / 34)
$$

The void fraction is thus higher, $V F=1,6 \cdot 10^{-9}$, and corresponds to a higher volume backscattering strength: $S_{v 7}=-41,5 \mathrm{~dB}$

The same analysis than in the previous section has been undertaken with the $S_{v 7}$ threshold in order to take into account the depth difference between the layers. In this case, the ratio of bubbled ping is always under $1 \%$, even with wind 
higher than 20 knots $(10 \mathrm{~m} / \mathrm{s})$. The detection of bubbles is significantly higher under the hull than in the natural sea sub-surface layer at the same depth.

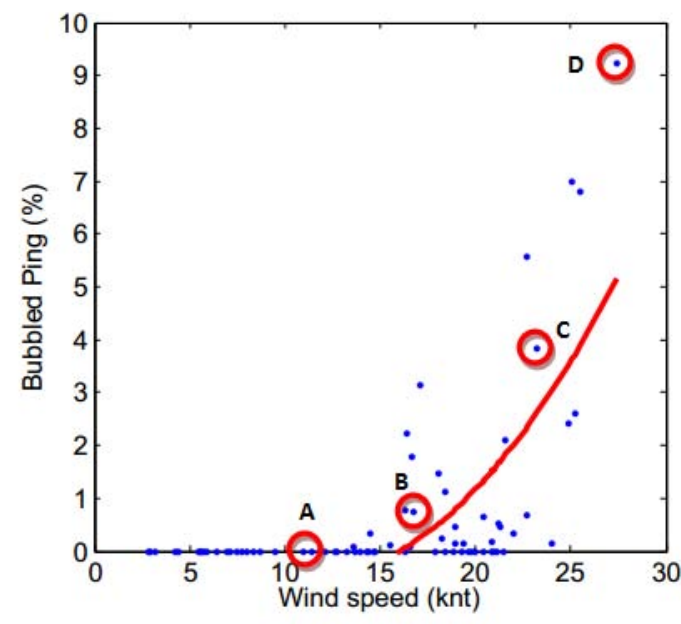

Figure 10: Influence of the wind on natural aeration: "Bubbled" Ping vs Wind Speed for the horizontally steered echosounder with a threshold $S_{v}=-50 \mathrm{~dB}$

However natural aeration can still be observed by the horizontal echosounder. Taking the initial threshold $S_{v}=-50 \mathrm{~dB}$, the evolution of bubble detection is very similar than in the first layer under the hull (figure 10). The four periods marked on figure 10 correspond to images A, B, C, D from the horizontal echosounder on figure 11. The horizontal axis represents the vessel's travel (1 mile between two vertical lines) and the vertical axis represents the distance to the sonar (graduated from 10 to 40 meters by step of $5 \mathrm{~m}$ ). The threshold of visualization is $-50 \mathrm{~dB}$. The mean wind speed on these periods are respectively $11 ; 17 ; 23$ and $27 \operatorname{knots}(5 ; 8 ; 11$ and $14 \mathrm{~m} / \mathrm{s})$. Image $\mathrm{A}$, with low wind, is very clean, and disruptions increase with the wind speed until a very noisy state on image $\mathrm{D}$ for which the wind begins to be strong.

This analysis indicates that the density of bubbles under the vertical sonar is similar than in the open sea sub-surface $2 m$ above. The specific flow generated by the ship's motions may carry these bubbles under the hull.

Furthermore it must be specified here that the bubble sweep-down occur- 


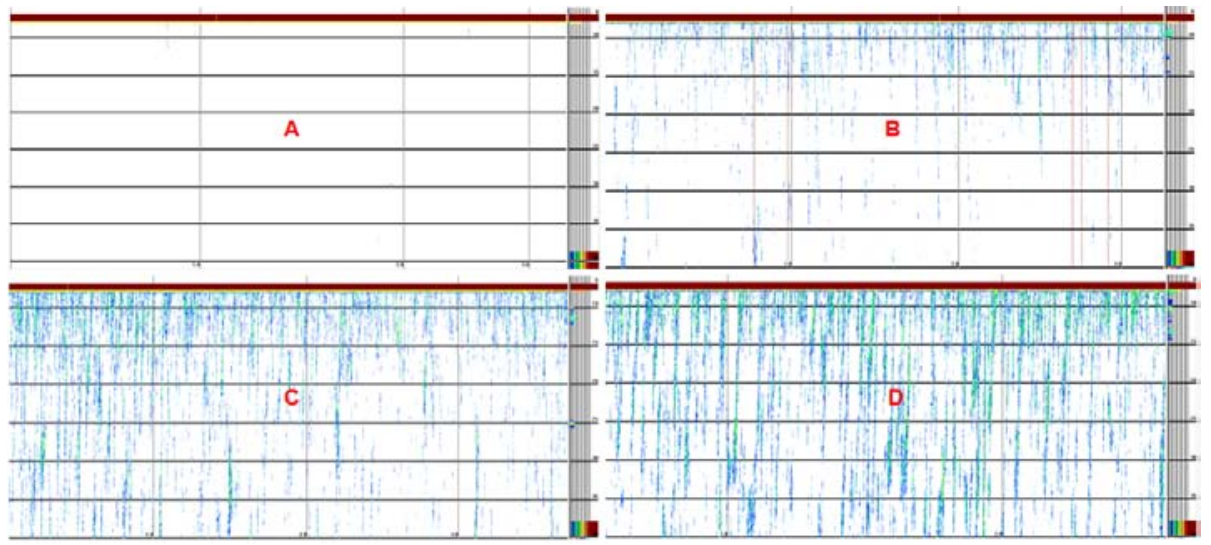

Figure 11: Visualization of bubbling by the horizontal echosounder for different wind speed. $\mathrm{W}=11 ; 17 ; 23$ and 27 knots respectively for periods $\mathrm{A}, \mathrm{B}, \mathrm{C}$ and $\mathrm{D}$. The acoustic perturbation levels can be identify by the density of dotted blue lines

rence is underestimated by the methodology of analysis of the vertical echosounder. Indeed a significant part of bubble clouds stays in the layer just below the hull (less than $2 \mathrm{~m}$ deep under the hull), where the echo-integration is not available.

\section{Comparison of bubble sweep-down occurrence with the Pourquoi}

\section{Pas?}

In order to test the developped method for bubble sweep-down characterization and to prove its consistency for another vessel, we analyzed a data base acquired during Pourquoi Pas? cruises. The Pourquoi Pas? is the main oceanographic research vessel of Ifremer fleet, equipped with a gondola for acoustic sensors installation (see figure 12). Three Simrad EA600 echosounders (12, 38, and $200 \mathrm{kHz}$ ) and a Reson ME70 multibeam echosounder in the range 12-100 $\mathrm{kHz}$ are installed on this vessel. We use for this study only a data base coming from the $200 \mathrm{kHz}$ sounder EA600 during a transit between Brest (France) and Pointe Pitre (Guadeloupe, Lesser Antilles) in November 2009. During this cruise, a wide variety of conditions has been encountered, with a maximum true wind speed of $73 \operatorname{knots}(37 \mathrm{~m} / \mathrm{s})$. 


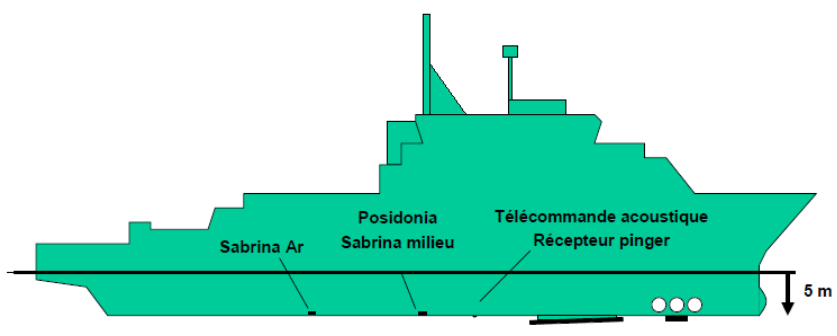

Figure 12: Pourquoi Pas ? with its acoustic equipment mounted on a gondola

The same methodology of acoustic data analysis used for the Thalassa database were applied for the data coming from the Pourquoi Pas ?:

- selection of stable periods in term of velocity (ship / wind) and heading - for stable periods (of 20 minutes):

- ship's motions and wind conditions analysis

- acoustic disturbances quantification

The figure 13 presents a comparison between Thalassa and Pourquoi Pas ? of the ratio of "bubbled" pings during a period in function of the true wind speed. These results show that the critical wind speed value, from which the number of "bubbled" pings is non negligeable, is the same for both vessels between 20 and 25 knots $(10$ and $13 \mathrm{~m} / \mathrm{s})$. For wind speed higher than 30 knots $(15 \mathrm{~m} / \mathrm{s})$, the number of "bubbled" pings reaches higher values for the Pourquoi Pas ? than for the Thalassa. For the analysed database, it is quite rare that the number of "bubbled" pings is higher than $15 \%$ for the Thalassa while it can reach $40 \%$ for the Pourquoi Pas?. Even if the two databases are not as complete as might be desired, these two vessels seems to have a different behavior from an acoustic point of view.

This result is confirmed by the comparison of the ratio of "bubbled" pings at $200 \mathrm{kHz}$ during a period in function of pitch standard deviation presented figure 14. On this picture, we can see that the ratio of "bubbled" pings is negligible for the Pourquoi Pas ? for a standard deviation of pitch less than $1^{o}$ while the Thalassa can be affected for small pitch variations. Furthermore, for pitch standard deviation higher than $1.5^{\circ}$ the ratio of "bubbled" pings increases 


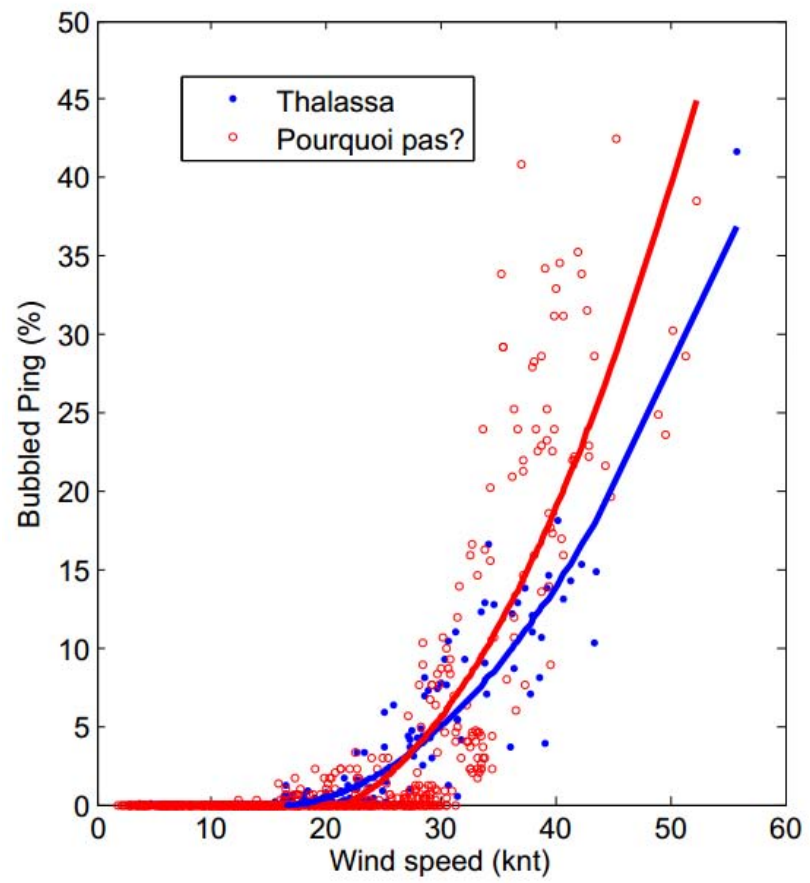

Figure 13: Comparison between the Pp? and Thalassa of the wind influence on bubble sweepdown

very quickly to reach values higher than $20 \%$ for the Pourquoi Pas, while these values are almost never reached for the Thalassa. Ratio of "bubbled" pings values higher than 5 to $10 \%$ are generally unusable for acoustic surveys.

These results show that this kind of analysis can be done to compare the "acoustic performances" of different kind of research vessels but also to quantify the limitations in term of condition at sea for acoustic survey [Delacroix [4]]. 


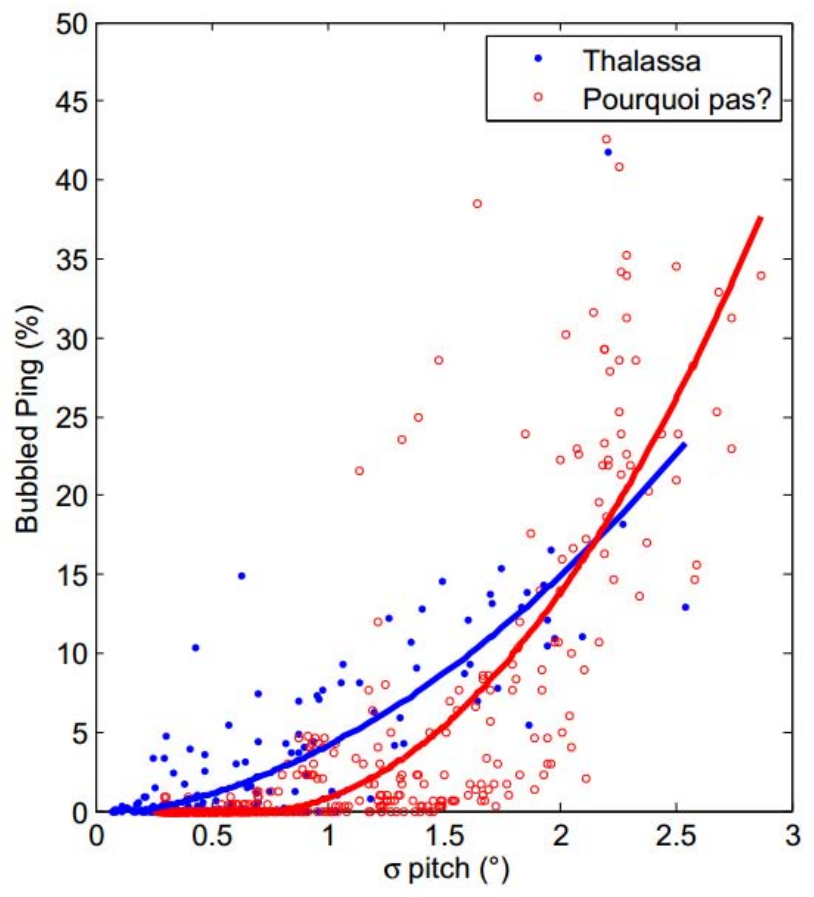

Figure 14: Comparison between the $\mathrm{Pp}$ ? and Thalassa of pitching on bubble generation

\section{Conclusion}

Direct detection of near resonance bubble clouds at 120 and $200 \mathrm{kHz}$ has been demonstrated using a simple threshold of the backscattered $S_{v}$ data that effectively separate bubbles from other scatterers as plancton. This method enables to compare, using calibrated echosounders, the percentage of bubbled pings for different platforms and different sea conditions. Such process has been implemented with both vertical and horizontal echosounder and allows to monitor bubble clouds just below the transducer but also outside the influence of the vessel. The correlation between the observations of bubbles and wind speed is strong $\left(R^{2}>0,8\right)$. Bubble clouds under the hull is generated by winds greater than $W_{c}=21$ knots $(10 \mathrm{~m} / \mathrm{s}$ ). The layer of observation is deep (8 to $10 \mathrm{~m}$ ) due to sounder blind zone and transducer near field. For natural bubble entrainments away from the vessel, the depth vary between 5,6 and 9, $5 \mathrm{~m}$. The 
analysis of bubbles distribution indicates that the void fractions in this layer of the open ocean is very similar than in the deeper layer under the vertical echosounder, which demonstrates the effect of bubble sweep-down.

This study confirms the influence of the sailing conditions on bubble sweepdown occurrence. The relation of this phenomenon with the depth has also been demonstrated. It is consequently appropriate to install the transducers at a greater depth to avoid this kind of problem. Though this precaution is not always sufficient and experiences of some vessels equipped with gondola are not always positive. The work of diminution of bubble propagation under the hull of a ship must start long before transducers mounting, from the design of bow shapes and the dynamical study of the ship.

The database used in this work may not be exhaustive, so further analysis with more sailing conditions and sea states, especially with different sorts of swell (short and large), are necessary. We thought first that in this particular working area of the eastern Channel and the North Sea, with shallow water, specific currents (as the Langmuir circulation) may drag more bubbles clouds under the surface layer than in deeper water. The analysis of data from Atlantic surveys coming from the Thalassa but also from data coming from the Pourquoi Pas ?, with larger swell and greater depth, doesn't confirm this hypothesis. Indeed, a larger statistical analysis doesn't give a better understanding of the influence of each parameter. The results presented in the study show that the proposed methodology of acoustic data analysis can be done to compare the "acoustic performances" of different kind of research vessels but also to quantify their limitations in term of condition at sea for which acoustic survey can be done. The comparison between Thalassa and Pourqoi Pas ?, though limited, allow to confirm that for wind speed above $20 \operatorname{knots}(10 \mathrm{~m} / \mathrm{s})$ and pitch greater than $2^{\circ}$ the Pourquoi Pas ? is more affected by surface bubbles with twice more bubbled pings observed.

Studies of the influence of meteorological conditions on the bubble distribution in the sea surface must be extended. Analysis of measures from seabed fixed sonar will be undertaken. These data should be compared to the observations 
made with horizontally oriented ship sonar and with results of previous study in the open ocean [Novarini \& Bruno [13], Thorpe \& Hall [16]] or in laboratory [Leifer \& al. [9]].

\section{Acknowledgements}

The authors gratefully acknowledge the DGA for the financial support granted for co-financed PhD these.

We would like to thank Yves Verin, in charge of IBTS cruises on the Thalassa for providing the data and allowing the active participation with specific trials on IBTS 2013. We are also grateful to the members of the acoustic department of Ifremer, for their assistance in the use of the echosounders.

\section{References}

[1] J. Dalen and A. Løvik, 1981. The influence of wind-induced bubbles on echo integration surveys. J. Acoust. Soc. Am. 69, 1653-1659.

[2] G. B. Deane and M. D. Stokes, 1999. Air entrainment processes and bubble size distributions in the surf zone. J. Phys. Oceanogr. 29, 1393-1403.

[3] G. B. Deane and M. D. Stokes, 2002. Scale dependence of bubble creation mechanisms in breaking waves. Nature. 418, 839-844.

[4] S. Delacroix, 2015. Caracterisation de la generation et de la propagation de bulles autour de la carene des navires scientifiques. PhD Universite de Bretagne Occidentale.

[5] D. A. Demer, G. R. Cutter, J. S. Renfree and J. L. Butler, 2009. A statistical-spectral method for echo classification. ICES J. of Marine Science. 66, 1081-1090.

[6] O. Dragesund and S. Olsen, 1965. On the possibility of estimating year-class strength by measuring echo-abundance of 0-group fish. Fiskeridirectoratets Skrifter, Serie Havunderskelser. 13, 48-75. 
[7] R. J. Korneliussen, N. Diner, E. Ona, L. Berger, and P. G. Fernandes, 2008. Proposals for the collection of multifrequency acoustic data. ICES J. of Marine Science. 65, 982-994.

[8] E. Lamarre and W. K. Melville, 1994. Void-fraction measurements and sound-speed fields in bubble plumes generated by breaking waves. J. Acoust. Soc. Am. 96, 1317-1328.

[9] I. Leifer, G. Caulliez and G. De Leeuw, 2006. Bubbles generated from windsteepened breaking waves: 2. Bubble plumes, bubbles, and wave characteristics. J. Geophys. Res. 111, 2156-2202.

[10] D.N. MacLennan, P.G. Fernandes, J. Dalen, 2002. A consistent approach to definitions and symbols in fisheries acoustics. ICES J. of Marine Science. 59, 365-369.

[11] H. Medwin and C. Clay, Fundamentals of Acoustical Oceanography, Academic Press, 1998.

[12] A. L. New, 1992. Factors affecting the quality of shipboard acoustic Doppler current profiler data. Deep-Sea Research. 39, 1985-1996.

[13] J. C. Novarini and D. R. Bruno, 1982. Effects of the sub-surface bubbles layer on sound propagation. J. Acoust. Soc. Am. 72, 510-514.

[14] D. Rolland and P. Clark, 2010. Reducing bubble sweepdown effects on research vessels, OCEANS'10 IEEE Sydney.

[15] F. W. Shabangu, E. Ona and D. Yemane, 2014. Measurements of acoustic attenuation at $38 \mathrm{kHz}$ by wind-induced air bubbles with suggested correction factors for hull-mounted transducers. Fisheries Research. 151, 47-56.

[16] S. A. Thorpe and A. J. Hall, 1983. The characteristics of breaking waves, bubble clouds, and near-surface currents observed using side-scan sonar. Continental Shelf Research. 1, 353-384. 
[17] S. A. Thorpe and T. R. Osborn and J. F. E. Jackson and A. J. Hall and R. G. Luek, 2003. Measurements of turbulence in the upper ocean mixing layer using Autosub. J. Phys. Oceanogr. 33, 122-145.

[18] S. A. Thorpe, The Turbulent Ocean, Cambridge University Press, 2005.

[19] V. M. Trenkel, V. Mazauric, and L. Berger, 2008. The new fisheries multibeam echosounder ME70: description and expected contribution to fisheries research. ICES J. of Marine Science. 65, 645-655.

[20] V.M. Trenkel, L. Berger, S. Bourguignon, M. Doray, R. Fablet, J. Mass, V. Mazauric, C. Poncelet, G. Quemener, C. Scalabrin, H. Villalobos, 2009. Overview of recent progress in fisheries acoustics made by Ifremer with examples from the Bay of Biscay. Aquat. Living Resour. 22, 433-445.

[21] M. V. Trevorrow, 2003. Measurements of near-surface bubble plumes in the open ocean with implications for high-frequency sonar performance. J. Acoust. Soc. Am. 114, 2672-84.

[22] S. Vagle and D. Farmer, 1998. A comparison of four methods for bubble size and void fraction measurements. IEEE J. Ocean. Eng. 23, 211-222.

[23] T. C. Weber, 2008. Observations of Clustering Inside Oceanic Bubble Clouds and the Effect on Short-Range Acoustic Propagation. J. Acoust. Soc. Am. 124, 2783-92. 